\title{
Introducing the EJHP Editorial Board
}

\section{Introducing the EJHP Editorial Board}

The launch of this brand new journal, published by the BMJ Group (BMJG) on behalf of the European Association of Hospital Pharmacists (EAHP), has been possible due to the hard work of the EJHP Editorial Board. We have been fortunate in retaining some of the original board members from the two former EJHP publications to work on the new journal as Associate and Deputy Editors, headed by Prof. Arnold G. Vulto as EJHP's Editorin-Chief, and we would like to take this opportunity to introduce you to the whole team.

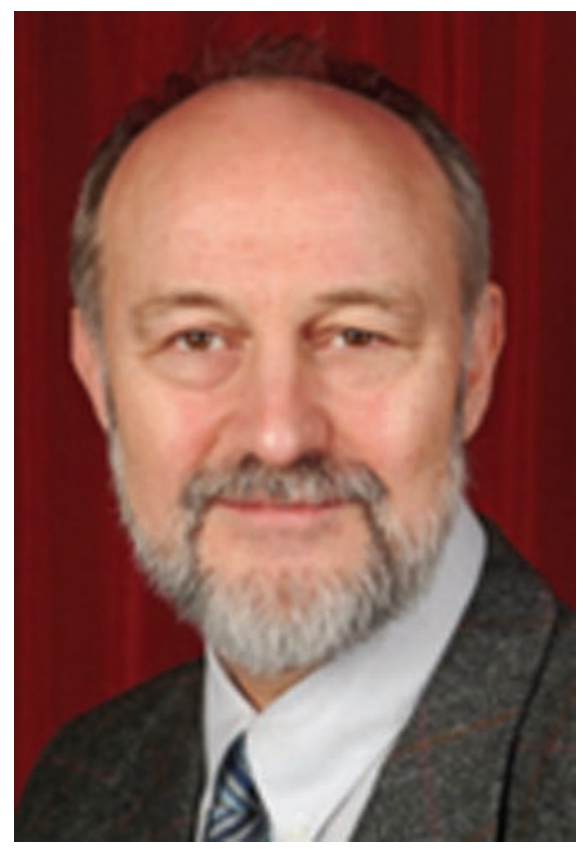

Editor in Chief:

Prof. Arnold G. Vulto

Current affiliation: Hospital Pharmacy, Erasmus University medical Centre Rotterdam, The Netherlands

Current status position: Professor of Hospital Pharmacy \& Practical

Therapeutics; in this capacity he is - together with Prof. Dr. Jan Danser - responsible for the undergraduate training of medical students at the Erasmus University Rotterdam in pharmacology and therapeutics. He is also Deputy Head of Hospital Pharmacy, Director of Research \& Education and the Preceptor for Hospital Pharmacy (6 residents in training).

Career History: 1987 - 1995: Head of the Hospital Pharmacy of the Veterinary Faculty, University of Utrecht (NL); 1995: Deputy head / Director of Research \& Education of the Erasmus MC Hospital Pharmacy in Rotterdam;

2004: Chair of Hospital Pharmacy \& Practical Therapeutics.

Education: Undergraduate Pharmacy Sudies: Gronngen University, The Netherlands and Dept. of Pharmacology, Cambridge University, UK;

Graduate studies: Experimental Pharmacology at the University of Utrecht;

$\mathrm{PhD}$ in Neurochemistry, Rudolf Magnus Institute, Utrecht University The Netherlands, and Dept. of Pharmacology, Karolinska Institute, Stockholm, Sweden;

Postgraduate training in Hospital Pharmacy: University Hospital Maastricht, The Netherlands.

Research interests: Clinical Pharmacology (pharmacokinetics / pharmacodynamics, clinical drug trials, pediatric clinical pharmacology); Pharmaceutical Biotechnology (pharmacogenetics, gene therapy).

Other achievements: Prof. Vulto is (co) author of $>100$ peer reviewed articles and supervised $15 \mathrm{PhD}$ projects;

He was an EAHP board member from 2002 - 2008 and chaired the EAHP Scientific Committee from 2003 - 2007.

EJHP responsibility: Editor-in-Chief, responsible for all papers, particularly the over-view of the practice content.

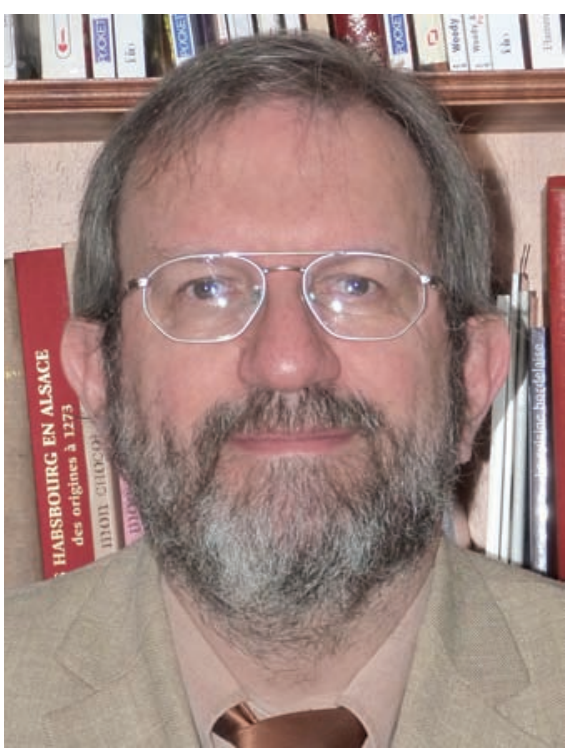

Associate Editor:

\section{Jean Vigneron}

Current affiliation: University Hospital of Nancy, France.

Current status position: Practice: preparation of cytotoxic drugs, quality control, and stability studies;

Teaching: co-organisation of a diploma in Oncology Pharmacy.

Career history: Hospital Pharmacist since 1985.

Research interests: Stability studies of injectable drugs mainly oriented to cytotoxic drugs.

Other achievements: Creator of STABILIS, the European database on the stability and compatibility of injectable drugs (www. stabilis.org);

President of the INFOSTAB association (www.infostab.com);

Member of the editorial board of the European Journal of Hospital Pharmacy 2005-2011;

Member of the board of the French Society of Oncology Pharmacy.

EJHP responsibility: Associate Editor predominantly responsible for practice article types, overseeing the peer review progress and then making a recommendation to the Editor-in-Chief. 


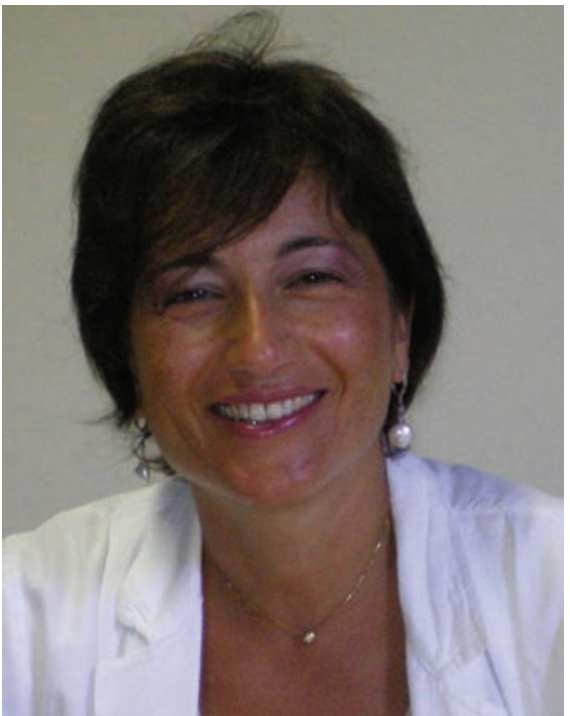

\section{Associate Editor:}

\section{Nicoletta Ambrogi}

Current affiliation: ASL 4, Terni, Italy

Current status position: Hospital Pharmacist Manager in the Department of Pharmaceutical care responsible for the monitoring and epidemiological analysis of drug consumption and pharmaceutical expenditure related to prescribing; expensive drugs distribution; investigation and administrative activities; supervision and inspections of community pharmacies.

Career history: 1984 - 1999: Pharmacist employee at community pharmacies; 2001 - 2002: Employed by Italian Ministry of Health in the III Department of Head Office for drugs assessment and control; 2004 - 2011: ASL 4, Responsible for the clinical trial, CEAS dialogist (Ethical Committee Regional Health Societies; 2011 - 2012: ASL 4, Therapeutic Committee Member.

Education: University of Perugia: Pharmacy Degree, PhD (1983); Post lauream Specialization course in "Pharmacoeconomics" (1999); Hospital Pharmacy Specialization (2001); 2002: "La Sapienza" University, Umberto I General Hospital, Rome: Post Lauream specialization in Clinical Bioethics; 2003: ISS (National Public Health Institute), Rome: XI Course of Pharmacoepidemiology; 2006: First training Course: Skills and Methods for pharmaceutical prescriptions analysis;

2010: University of Camerino, Italy: University Master's Degree 'Pharmaceutical Manager Departments'.

Other achievements: Member of SIFO (Italian Society of Hospital Pharmacists) and
SIFO regional secretary (UMBRIA Region) since 2004, with the task of organizing scientific and cultural activities and to act on behalf of SIFO with the Institutions at regional level;

Chairwoman/Spokeswoman of regional events ECM, with SIFO Provider and attends national SIFO Congress in several sessions;

Member of Italian Delegation of EAHP (European Association of Hospital Pharmacists) since 2006, appointed Head of Italian Delegation in 2009;

Member of the editorial board of the European Journal of Hospital Pharmacy 2007-2011;

EAHP - Pharmine Group Member 2010-2011;

Scientific Committee Member of $17^{\text {th }}$ Congress of EAHP 2012.

EJHP responsibility: Associate Editor - responsible for specific practice papers, assigned by the Editor-in-Chief, overseeing the peer review process and then making a recommendation to the Editor-in-Chief.

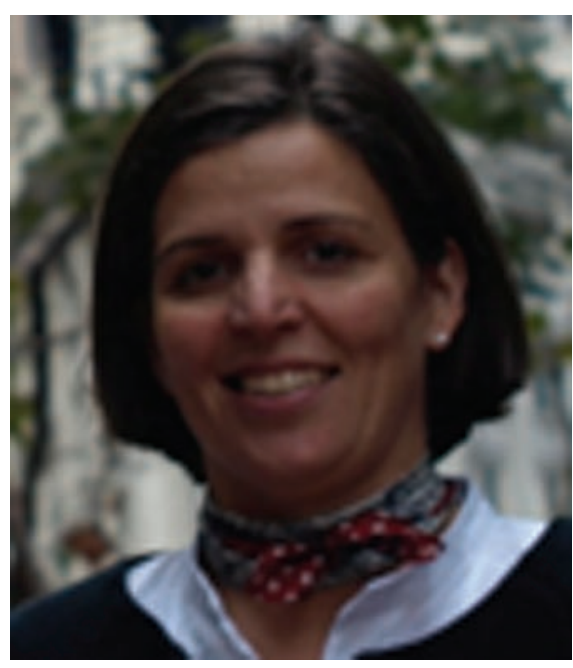

\section{Associate Editor:}

\section{Dr. Ana Herranz}

Current affiliation: Hospital Gregorio Marañón, Madrid, Spain.

Current status position: Operations Manager for 18000 bed university hospital, including IT responsibilities to improve the quality of health assistance by patient centred care and to achieve effective, safe and efficient pharmacotherapy.

Education: PhD.: University of Navarra, Pamplona, Spain.

Career history: Hospital Pharmacy specialist since 1997.
Research interests: Pharmacy practice, Hospital pharmacy administration.

Other achievements: Member of the editorial board of the European Journal of Hospital Pharmacy.

EJHP responsibility: Associate

Editor - responsible for specific practice papers, assigned by the Editor-in-Chief, overseeing the peer review process and then making a recommendation to the Editor-in-Chief.

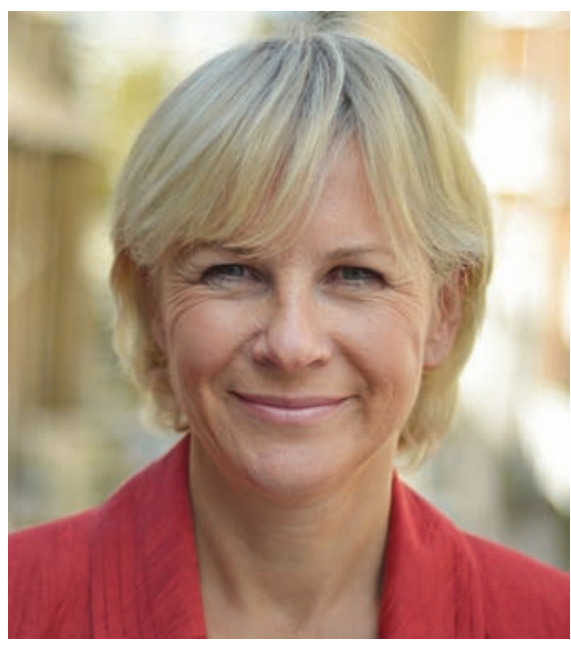

Associate Editor:

\section{Catherine Mooney}

Current affiliation: Director of Governance and Corporate Affairs, Chelsea \&

Westminster Hospital NHS Foundation Trust, London, UK

Current status position: Clinical, corporate and quality governance, encompassing patient safety, clinical effectiveness, clinical audit, legal affairs, risk and compliance. Production of the hospital Quality Account and management of the Board.

Career history: Chief Pharmacist at St. Mary's NHS Trust in London for 15 years;

Clinical Governance Manager at Hammersmith Hospitals Trust (now Imperial Healthcare) for 2 years.

Education: BSc Pharmacy, University of Belfast, UK;

MSc Clinical Pharmacy, School of Pharmacy, University of London, UK.

Other achievements: Chair of the joint UKCPA/GHP Leadership Development Group;

Led risk management course for Spanish pharmacists for 3 years;

Keynote speaker at EAHP Congress 2006 on 'risk management'Member of the editorial board of the European Journal of Hospital Pharmacy. 
EJHP responsibility: Associate Editor - responsible for specific practice papers, assigned by the Editor-in-Chief, overseeing the peer review process and then making a recommendation to the Editor-in-Chief.

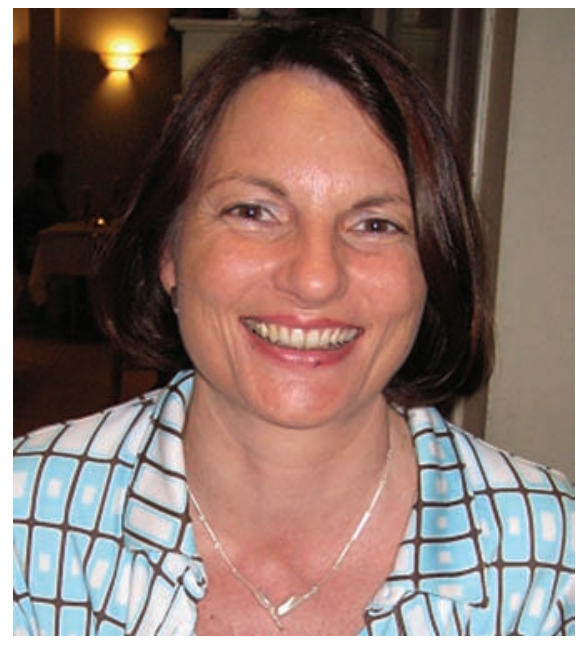

\section{Associate Editor:}

\section{Ute Spöhrer}

Current affiliation: Hospital Pharmacy of the Munich University Hospital, Germany.

Current status position: Senior hospital pharmacist.

Career history: Clinical pharmacist; specialist in intensive care.

Education:Trained as a pharmacist and later hospital pharmacist in Germany;

MBA in Health Care Management, University of Trier, Germany.

Research interests: Pharmacokinetics, Toxicology, Health economics.

Other achievements: Chosen for a special training program designed for high potential hospital pharmacists by the German Society of Hospital Pharmacists;

Member of the editorial board of the European Journal of Hospital Pharmacy.

EJHP responsibility: Associate Editor - responsible for specific practice papers, assigned by the Editor-in-Chief, overseeing the peer review process and then making a recommendation to the Editor-in-Chief.

\section{Associate Editor:}

\section{Juraj Sykora}

Current affiliation: National Cancer Institute, Slovakia.
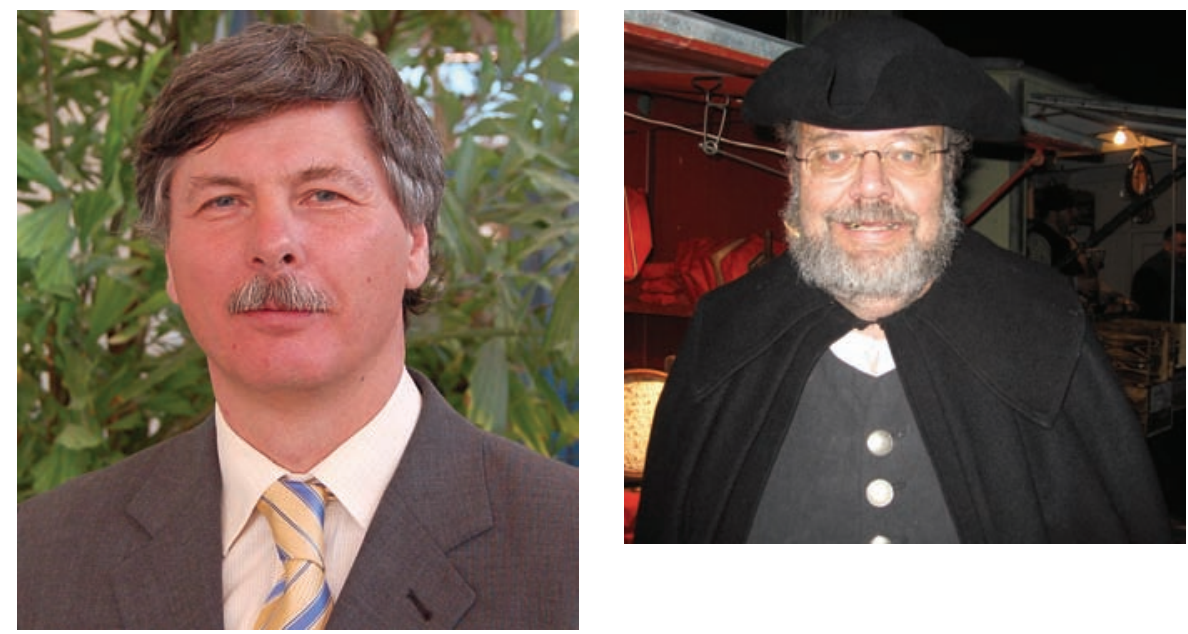

Science Editor:

\section{Prof. Per Hartvig Honoré}

Current status position: Oncology pharmacist in the pharmacy department, National Cancer Institute;

Director of the Pharmacy Institute at the Slovak Health University.

Career history: 1983-1989: Clinical pharmacist in the National Institute for Respiratory Diseases in Bratislava;

1987-1994: Hospital pharmacist and junior lecturer in the University Hospital akademika Derera and in the Postgraduate Medical School in Bratislava;

1994-2005: Director of hospital pharmacy in National Cancer Institute, Bratislava;

2005-2007: Employed in the Pharmacy

Department of the Ministry of Health of the Slovak Republic;

2007-2011: Hospital pharmacist in National Cancer Institute and Director of Pharmacy Institute, Slovak Health University.

Education: 1983: Pharmacist diploma, Comenius University of Bratislava.

Research interests: Basic pharmacology as a research of potential anti-inflammatory drugs, stability of infusion mixtures and hospital pharmacy.

Other achievements: President of the Section of Hospital Pharmacists of the Slovak Chamber of Pharmacist;

Member of the editorial board of the European Journal of Hospital Pharmacy;

Member of the EAHP board (European Association of Hospital Pharmacists);

Lectured and published several articles on pharmacy.

EJHP responsibility: Associate Editor, responsible for specific practice papers, assigned by the Editor-in-Chief, overseeing the peer review process and then making a recommendation to the Editor-in-Chief. Current affiliation: University of
Copenhagen, Denmark.

Current status position: Professor in Pharmacokinetics and Pharmacodynamics.

Career history: 1977-1990: Assistant professor, Uppsala University, Sweden; 1990-2002: Adjunct professor in bioanalysis and pharmacokinetics; 2002-2008: Guest professor, Neuroscience School, University of Copenhagen, Sweden; 2008-2011: Professor in

Pharmacokinetics and Pharmacodynamics, University of Copenhagen, Denmark.

Education: 1969: Pharmacist undergraduate, Uppsala University, Sweden;

1974: PhD in analytical chemistry, Uppsala University, Sweden.

Research interests: Bioanalysis of drugs and metabolites with studies on pharmacokinetic-pharmacodynamic PK-PD relations of drugs used for neurologic or psychiatric diseases, nausea and pain as well for antibiotics and cytotoxic drugs.

Other achievements: Previously: supervised over 40 students in clinical pharmacy and in pharmacotherapy for master degree in pharmacy; supervised $25 \mathrm{PhD}$ students in analytical chemistry, drug metabolism and kinetics, psychiatry, neurology, anesthesia, positron emission tomography.

Lectured on nuclear medicine, pharmacology and drug therapy in the Pharmaceutical and Medical faculty at the universities of Uppsala and Copenhagen; a member of the Drug Information Centre, the local Antibiotic Surveillance Board and the Drug Committee.

Founded the Scandinavian Network for Oncology Pharmacy Practice.

Presently: secretary for European Society of Oncology Pharmacy; 
Responsible for advanced courses in Good Manufacturing Practice, Nuclear medicine, PK-PD and Analgesiology at Uppsala University;

Board member of the Danish Pharmaceutical Society, and on the board for the section of Clinical Pharmacy;

Member of the editorial board of the European Journal of Hospital Pharmacy The number of publications in peer reviewed journals amounts 380 .

EJHP responsibility: Science Editor, responsible for the leadership of the Science section in collaboration with Dr. V'lain Fenton May, Prof. Stephan Mühlebach and Dr. Jean-Daniel Hecq as Deputy Editors.

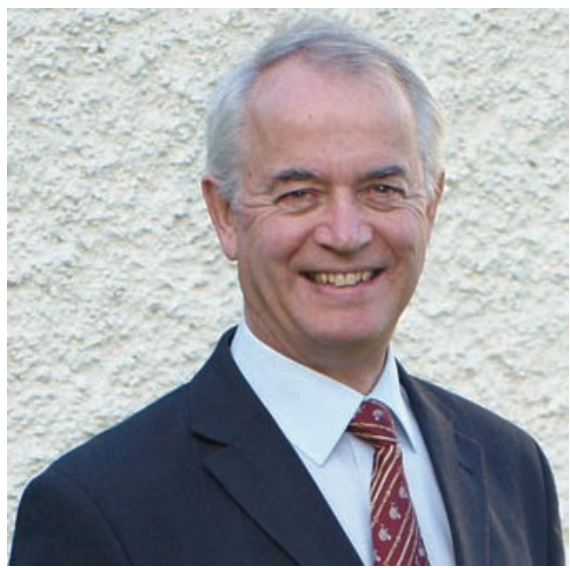

Deputy Editor:

\section{V'lain Fenton-May}

Career history: Formally Quality Control Pharmacist, Wales (now retired).

Education: Studied Pharmacy at the University of Bradford, UK.

Research interests: Manufacture, Quality Control, Formulation, Procurement and Distribution.

Other achievements: Chairman of the British Pharmacopoeia Commission; UK delegate to the European

Pharmacopoeia Commission; Member of the Chemistry \&

Pharmacy Standards Committee of the UK Commission on Human Medicines Past President of the Guild of Hospital Pharmacists (UK);

Member of the editorial board of the

European Journal of Hospital Pharmacy;

UK delegate to the EHP assembly

(1984-1992).

EJHP responsibility: Deputy Editor, responsible for the peer review progress of science papers assigned to him by the Science
Editor, and once all reviews are returned, will then make a recommendation to the Science Editor.

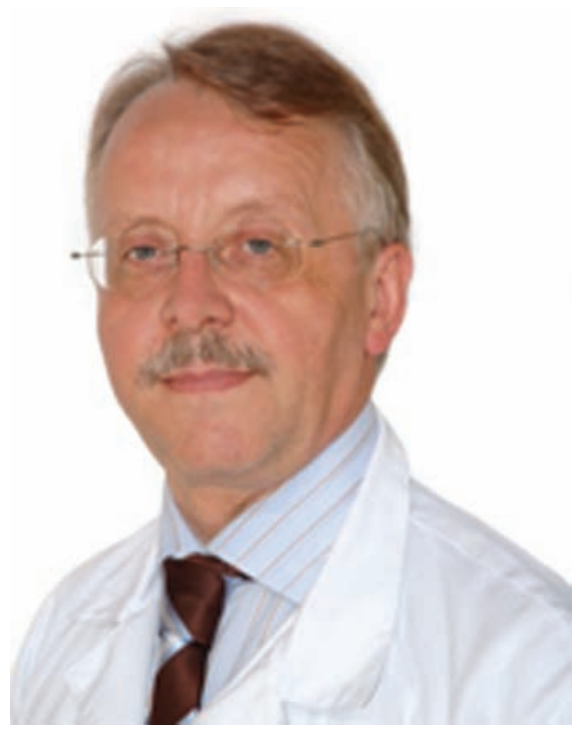

Deputy Editor:

Jean Daniel Hecq

Current affiliation: CHU Mont-Godinne Pharmacy, Belgium.

Current status position: Head of Department of Pharmacy (2009-2011).

Career history: Hospital Pharmacist, University Hospital U.C.L. of MontGodinne, Belgium (375 beds) 1979, Head of Pharmacy 1989.

Education: 1977: Diploma of Pharmacist; 1978: Graduate of Hospital

Pharmacist, University Catholique de Louvain, Belgium;

1992: Certificate in Formation in Hospital Hygiene;

2003: Certificate in Management of the Anti-infectious Therapy (inter-University Program UCL - ULB - ULG);

2005: Diploma of in-depth studies in sciences of health, pharmaceutical sciences with great distinction;

2005: University certificate in Clinical Pharmacy;

2006: Diploma of Doctor of

Pharmaceutical Sciences;

2011: Inter-University certificate

Catholic University of Louvain-Ulb in Medical Management.

Research interests: Study of long-term stability of reconstituted for ready-to-use injectable drugs after microwave freeze-thaw treatment or conventional storage.

Other achievements:1987: External consultant of the department of Pharmacy, University of Namur, Belgium;
2009: Founder and coordinator of Drug Research Stability Group, CHU MountGodinne;

Instructor of training period for the students technician in Pharmacy at the:

- Institut de la Providence à Ciney

- Institut Félicien Rops à Namur

- Institut Technique de Namur

1997-2011: President and vice-president of the ABPH - BVZA);

Member of a number of societies and associations including European Association of Hospital Pharmacy (EAHP) and member of Editorial Advisory Committee for the European Journal of Hospital Pharmacy (2002-2011);

Editor responsible for the 'Pharmakon Forum of the Hospital Pharmacists' (2003-2005 and2007-2009);

Coordinator of the Belgian database 'Stability of injectable drugs in infusion' for the previous 30 years.

EJHP responsibility: Deputy Editor, responsible for the peer review progress of science papers assigned to him by the Science Editor, and once all reviews are returned, will then make a recommendation to the Science Editor.

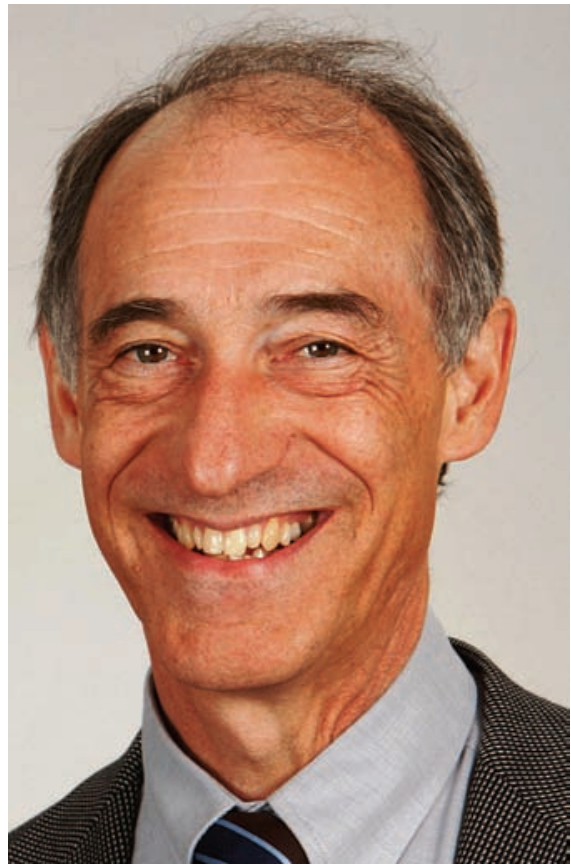

Deputy Editor:

\section{Prof. Stefan Mühlebach}

Current affiliation: Global Regulatory Affairs of Vifor Pharma Ltd.

Current status position: Scientific Director of Global Regulatory Affairs of Vifor Pharma Ltd. University 
activities in research, pregraduate and postgraduate teaching and direction of theses ( $\mathrm{PhD}, \mathrm{MD}, \mathrm{Ms}$ ).

Career history: 1975-1980: Research fellow at the University of Bern, Switzerland;

1980-1987: Head of hospital pharmacy, Biel (1980-1987) and Aarau (until 2005);

1993: University teacher, Bern

2000: University teacher, Basel

2004: Professor of Pharmacology and

Hospital Pharmacy for the Department of Pharmaceutical Sciences;

2005-2007: Head of the Swiss

Pharmacopoeia and the Swiss delegation at EDOM;

Consultant in clinical nutrition and hospital pharmacy at the University Hospital; 2008-2011:Scientific director of Global Regulatory Affairs at Vifor Pharma Ltd.

Education: 1975: Pharmacy diploma, University of Bern, Switzerland; 1979: $\mathrm{PhD}$ in pharmacology and toxicology University of Bern, Switzerland.

Research interests: Pharmacology, Clinical Nutrition, Regulatory Affairs;

Hospital pharmacy practice \& education: pharmacokinetics, TDM, clinical nutrition;

Drug evaluation (formulary, manufacture, regulatory aspects).

Other achievements: Over 50 PubMed publications, book chapters;

Editorial adviser of scientific journals;

EAHP delegate (1984-2005); board member (1992-1996);

President of the Committee for education and training in hospital pharmacy, Switzerland (1999-2005);

Secialist in hospital pharmacy (teacher) and pharmaceutical care of nursing homes (2001);

Vice president of the Swiss Academy of Pharmaceutical Sciences \&Fellow of the Swiss Society of Pharmaceutical Sciences (since 2009).

EJHP responsibility: Deputy Editor, responsible for the peer review progress of science papers assigned to him by the Science Editor, and once all reviews are returned, will then make a recommendation to the Science Editor.

The European Journal of Hospital Pharmacists: Science and Practice is the official journal of the European Association of Hospital Pharmacists (EAHP), here is an opportunity to meet the president, Dr Roberto Frontini, and the Director of
Professional Development, Tajda Miharija Gala.

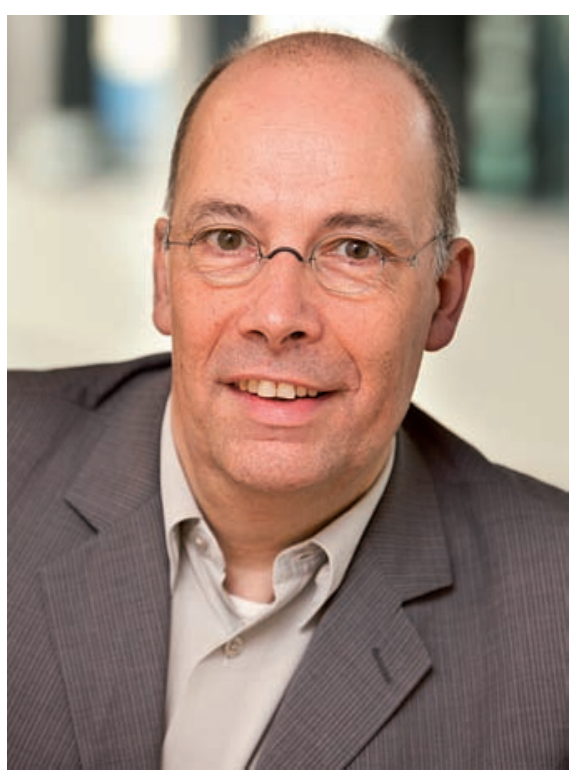

EAHP President:

\section{Dr. Roberto Frontini}

Current affiliation: University Hospital of Leipzig, Germany; European Association of Hospital Pharmacists (EAHP).

Current status position: 2001-2011: Director of Pharmacy at the University Hospital of Leipzig;

2009-2011: President of EAHP.

Career history: 1993-1995: Employed by

University Hospital of Leipzig; 1996-2001: Head of Pharmacy at

St.Franziskus-Hospital,Cologne;

2001-2011: Director of Pharmacy at the University Hospital of Leipzig from 2001;

2005-2009: Director of Finances of the European Association of Hospital Pharmacists (EAHP);

2009-2011 President of European Association of Hospital Pharmacists.

Education: 1988-1992: Pharmacy, University of Hamburg, Germany;

1993: Phd in pharmaceutical technology, University of Hamburg, Germany;

1996: Specialisation degree in Hospital Pharmacy.

Research interests: Patient safety.

Other achievements: 1994 to 2005: Served in a training position for pharmaceutical technology at the Chamber of Pharmacy Hannover;

2004-2011: Lectured on

Pharmacoepidemiology and Economics at the University of Leipzig, School of Pharmacy.
EAHP responsibility: The president has a number of responsibilities, primarily including that of presiding as chief executive officer of the association, leading all meetings of the association and of the Board. He has the general and active management of the affairs of the association and sees that all orders and resolutions of the Board are carried into effect.

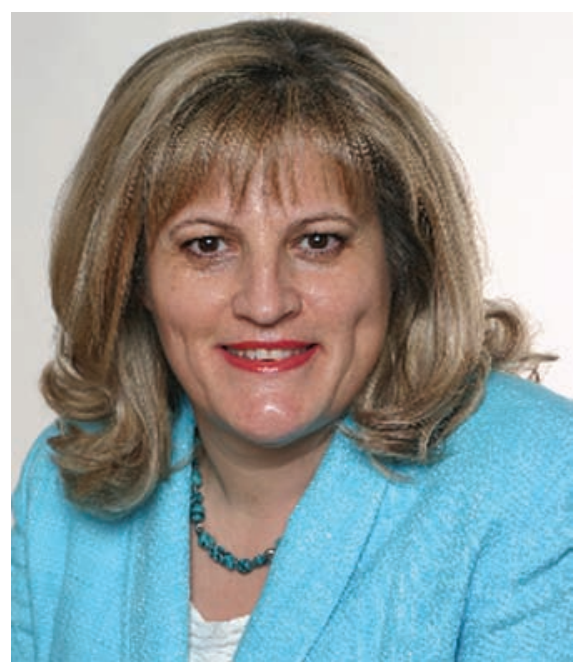

EAHP Director of

Professional Development:

Tajda Miharija Gala

Current affiliation: University Medical Centre, Ljubljana, Slovenia.

Current status position: Hospital Pharmacist, Quality.

Career history: 1979-1981: Community pharmacy;

1981-1992: Hospital pharmacist, University Medical Centre, Ljubljana, Slovenia;

1992-1997: Head of drug preparation laboratory, University Medical Centre, Ljubljana, Slovenia;

1997-2010: Director of Hospital Pharmacy, University Medical Centre, Ljubljana, Slovenia;

2010-2011: Hospital pharmacist Quality, University Medical Centre, Ljubljana, Slovenia.

Education: 1979: Diploma - Master of Pharmacy;

1990: Specialisation - Specialist of Pharmaceutical Technology; 2000: Programme for Pharmacy Managers, GEA College Ljubljana; 2005/2006: Postgraduate studies at the University of Ljubljana, Faculty of Pharmacy.

Research interests: Health sector management (management of colorectal cancer), National formulary for tissue repair. 
Other achievements: Slovenian Pharmaceutical Society (SFD): Active as a member of the organizing committee (1993-1995, 1997-1999); member of the editorial board of Farmacevtski Vestnik, official journal of SFD (1997 - 1999);

served as President of SFD (1995 - 1997);

2001: Won the Minarik award for the contribution to the development of the Slovenian pharmacy and for her work at the Slovenian Pharmaceutical Society;

Slovenian Chamber of Pharmacy: Active member of the educational board (1996 - 1998); chairperson of the Committee for Pharmaceutical Affairs (1998-2000);

Member of the organizing committees of the educational seminars (1997 - 2000);

Member of the Monitoring and Advisory Board (1995 - 2010);

Member of the project on Strategic and Procedural Guidelines for Operation of Hospital Pharmacies in Slovenia (2007 - 2009);

The Ministry of Health: Member of the National Committee for Assessment of Conditions for Pharmacy Activities verification of pharmacies (2001 - 2010).

Member of the Professional Advisory Board for Pharmacy to the Ministry of Health (since 2008);

FIP: Assistant secretary of the hospital section of FIP (2000)

EAHP responsibility: Member of the Managing Board of EAHP as Director of Professional Development.

European Journal of Hospital Pharmacy 2012;19:7-12.

doi:10.1136/ejhpharm-2012-000077 